\title{
Brain Lipid Binding Protein (FABP7) as Modulator of Astrocyte Function
}

\author{
M. KIPP ${ }^{1,2}$, T. CLARNER ${ }^{2}$, S. GINGELE ${ }^{2}$, F. POTT ${ }^{2}$, S. AMOR ${ }^{2,3}$, P. VAN DER VALK ${ }^{2}$, \\ C. BEYER ${ }^{1}$
}

${ }^{1}$ Institute of Neuroanatomy, Faculty of Medicine, RWTH Aachen University, Aachen, Germany, ${ }^{2}$ Department of Pathology, VU University Medical Center, Amsterdam, The Netherlands, ${ }^{3}$ Neuroimmunology Unit, Queen Mary University of London, Neuroscience Centre, Blizard Institute of Cell and Molecular Science, Barts and The London School of Medicine and Dentistry, London, UK

Received February 2, 2011

Accepted February 16, 2011

On-line July 19, 2011

\section{Summary}

Over a century ago, hyperplasia and hypertrophy of astrocytes was noted as a histopathological hallmark of multiple sclerosis and was hypothesized to play an important role in the development and course of this disease. However until today, the factual contribution of astrocytes to multiple sclerosis is elusive. Astrocytes may play an active role during degeneration and demyelination by controlling local inflammation in the CNS, provoking damage of oligodendrocytes and axons, and glial scarring but might also be beneficial by creating a permissive environment for remyelination and oligodendrocyte precursor migration, proliferation, and differentiation. Recent findings from our lab suggest that brain lipid binding protein (FABP7) is implicated in the course of multiple sclerosis and the regulation of astrocyte function. The relevance of our findings and data from other groups are highlighted and discussed in this paper in the context of myelin repair.

\section{Key words}

Multiple sclerosis • Oligodendrocyte • Astroglia • Regeneration • Remyelination

\section{Corresponding author}

Markus Kipp, Institute of Neuroanatomy, RWTH Aachen, Wendlingweg 2, D-52074 Aachen, Germany. Fax: +49 (0) 24180 82 472. E-mail: mkipp@ukaachen.de

\section{Astroglia: General remarks}

It is well-known that glial cells are more than 'glue'-material between neurons, a "function" originally suggested by Rudolf Virchow in the mid $19^{\text {th }}$ century. Astrocytes represent a subpopulation of macroglia in the peripheral and central nervous system (CNS). Since the late nineteenth century, astrocytes have been divided based on their morphology into two main subtypes: protoplasmic (lat. astrocytus protoplasmaticus) and fibrous astrocytes (lat. astrocytus fibrosus). Protoplasmic astrocytes are present throughout the gray matter and exhibit morphological characteristics such as several stem branches that, in turn, give rise to finely branching processes in a uniform globoid distribution. In contrast fibrous astrocytes are found throughout the white matter and display many long fibre-like processes (from Ramon Y, Cajal S; 1909: Histologie du systeme nerveux de l'homme et des vertebres). Astroglia function exceeds by far a solely supportive role in neural tissue. These cells are dynamic, capable of communicating with neurons and other glial cells. Their processes extend to neuronal synapses, nodes of Ranvier, and to the blood-brain barrier (BBB), and they are interconnected via gap junctions to each other as well as to oligodendrocytes (Venance et al. 1995, Rash et al. 2001). Astroglia are essential for the physical structuring of the brain, metabolism, and

PHYSIOLOGICAL RESEARCH • ISSN 0862-8408 (print) • ISSN 1802-9973 (online)

(c) 2011 Institute of Physiology v.v.i., Academy of Sciences of the Czech Republic, Prague, Czech Republic

Fax+420 241062 164, e-mail: physres@biomed.cas.cz, www.biomed.cas.cz/physiolres 
synaptic functioning in addition to their role in responding to pathological insults. Such insults provoke a graded cellular activation referred to as reactive gliosis (Faulkner et al. 2004, Pekny and Nilsson 2005).

There is a growing body of evidence suggesting that the loss of normal astrocyte function or acquisition of non-physiological properties contribute to, or are even considered as, the primary cause of the genesis of human brain diseases. Alexander disease (AD) represents one of those disorders linking astrocyte dysfunction with disease pathogenesis (Li et al. 2002, Quinlan et al. 2007, Sawaishi 2009). AD is a progressive, usually fatal neurological disorder, and can be divided into an infantile, juvenile, and adult form. Although all three forms of $\mathrm{AD}$ can differ markedly in their clinical, paraclinical, and pathological presentation, they are united by the abundance of so-called "Rosenthal fibers" which are protein aggregates within astrocytes composed inter alia of glial fibrillary acidic protein (GFAP), $\alpha \mathrm{B}$-crystallin, and heat shock protein 27 (Ma et al. 2007). AD is a rare genetic disorder caused by mutations in the gene for GFAP - a type III intermediate filament protein transcribed from a $10 \mathrm{~kb}$ region located on chromosome 17 in humans and 11 in the mouse. Mice lacking this intermediate filament protein still display normal development and reproduction (Pekny et al. 1995). In contrast, astrocytes of transgenic mice with an overexpression of the human GFAP gene, reveal inclusions resembling Rosenthal fibres (Messing et al. 1998). Following these interesting findings, Brenner and colleagues showed that heterozygous miss-sense mutations of GFAP are associated with AD, establishing this rare disorder as the first example of a primary genetic disorder of astrocytes (Brenner et al. 2001).

Another example of a dysfunction of astrocytes associated with brain pathology is neuromyelitis optica. Neuromyelitis optica (NMO or Devic's disease) is a severe autoimmune inflammatory and demyelinating disease of the CNS which predominantly affects the spinal cord and the optic nerve (Jarius and Wildemann 2010, Saikali et al. 2009). Although previously referred to as a subtype of multiple sclerosis (MS), the recent description of NMO-IgG, a highly disease-specific autoantibody found in NMO but absent in the classical form of MS, convincingly demonstrated that NMO is a specific disease and not just a subtype of MS. The target antigen of NMO-IgG was identified as aquaporin-4 (AQP4), the main water channel protein in the CNS, expressed on astrocyte end-feet at the $\mathrm{BBB}$ and brain- cerebrospinal fluid-barrier (Lennon et al. 2004). AQP4 plays a crucial role in the regulation of water fluxes from the extra- to the intracellular compartment in the CNS. A series of clinical and pathologic observations strongly suggest that auto-antibodies directed against astrocytic AQP4 play a central role in the physiopathology of NMO (Jarius et al. 2008).

\section{Astroglia: Relevance for multiple sclerosis}

MS, also known as disseminated sclerosis or encephalomyelitis disseminata, is a chronic, inflammatory, and demyelinating disease that affects the CNS. It is the most common neurological disorder in young adults in the Western hemisphere with a female prevalence. MS appears in several courses with new symptoms either in discrete episodes (relapsing-remitting form) or slowly accumulating over time (progressive form). Most patients are diagnosed with relapsingremitting MS but enter at later stages the secondaryprogressive stage. Between such episodes, symptoms may disappear completely. However, neurological problems often persist, especially as disease progresses. Besides lymphocytes and other leukocytes, astroglia and microglia contribute to the cellular composition of inflammation in MS lesions (van der Valk and De Groot 2000). As stated above, astroglia are pivotal regulators of intra-cerebral inflammatory processes and are required to protect nerve cells from pathological threats. Activation, proliferation, and morphological alterations of astrocytes are histopathological hallmarks of human MS and its related animals models such as experimental autoimmune encephalomyelitis (EAE) and toxin- and virus-induced demyelination (Gold et al. 2006, Lassmann 2008, Kipp et al. 2009).

Following the trend-setting documentation of gross anatomical changes in the CNS of MS patients by R. Carswell (1883), J. Cruveilhier (1829) and G.T. Valentiner (1856), the first detailed description of microscopic pathology of MS is ascribed to J.M. Charcot. In 1868, he published the manuscript "Histologie de la sclerose en plaque" (Gaz Hopital, Paris, 41:554-566) summarizing previous reports and adding his own clinical and pathological observations (Lassmann 2005). The terms "disseminated sclerosis" or "encephalomyelitis disseminata" describe the main pathological findings in the MS brain which are disseminated sclerotic plaques. The sclerotic aspect is due to a tissue scar formed by astrocytes. In the most common (Charcot) type of MS, 
plaques of demyelination are interspersed with and surrounded by reactive astrocytes. In addition, widespread focal reactive astrogliosis of varying intensity throughout white and gray matter is characteristic of the disease. Astrocytes during MS may also demonstrate the phenomenon of 'emperipolesis', i.e., an astrocyte apparently engulfing one or more other cells such as oligodendroglia (Ghatak 1992) and lymphocytes (Furer et al. 1993). The role of astrocytes during MS and related disorders is under intense investigation. Astrocytes play an active role during degeneration and demyelination by promoting inflammation, damage of oligodendrocytes and axons, and glial scarring but might also be beneficial by creating a permissive environment for remyelination and oligodendrocyte precursor migration, proliferation, and differentiation. Astrocytes secrete a multitude of harmful cytokines such as tumor necrosis factor alpha (TNF- $\alpha$ ) or interleukin $1 \beta$ (IL-1 $\beta$ ) as well as proinflammatory prostaglandins (Karakaya et al. 2007, Johann et al. 2008, Kipp et al. 2008). This makes it likely that astrocytes are implicated in oligodendrocyte damage and, in consequence, in promoting demyelination. Furthermore, it has been shown that the glycosaminoglycan hyaluronan, synthesized by activated astrocytes accumulates in chronically demyelinated human MS lesions and inhibits oligodendrocyte progenitor (OPC) differentiation and consequently remyelination (Back et al. 2005). On the other hand, astrocytes might contribute to regeneration and remyelination by secreting important growth factors, i.e., platelet-derived growth factor (PDGF), insulin-like growth factor 1, and basic fibroblast growth factor. All of these factors are known to promote remyelination and prevent oligodendrocyte apoptosis. Of relevance is a recently published review article which focuses on astrocytes as producers of secreted factors that can either promote or impede myelination within the CNS and how these cells are currently thought to be involved in the myelin pathology of MS (Moore et al. 2011).

We stress at this point that the secretion of proinflammatory molecules such as TNF- $\alpha$ or IL- $1 \beta$ from astrocytes does not necessarily have a negative impact on MS disease progression. The importance of inflammation for endogenous remyelination is well-documented (Patani et al. 2007). The cytokines TNF- $\alpha$ and IL-1 $\beta$ promote proliferation of oligodendrocyte progenitors and remyelination (Arnett et al. 2001, Mason et al. 2001). Major histocompatibility complex-II (MHC-II)-null mice display delayed remyelination and regeneration of oligodendrocytes compared to their wild type littermates after cuprizone or Theiler's virus-induced demyelination (Njenga et al. 1999, Arnett et al. 2003). Furthermore, the activation of inflammatory response by a combination of growth factors leads to myelin repair (Biancotti et al. 2008) clearly demonstrating a beneficial role for inflammation in the CNS. Other factors related to inflammation, such as interferon- $\gamma$ (Lin et al. 2006, Mana et al. 2006), however, might be more detrimental for remyelination. Understanding of the dual role of inflammatory cytokines/factors to enable control and manipulation of these responses thus represents a major goal for the development of new therapies.

\section{Astrocytes adopt different functions during their lifespan and pathological challenges}

One intriguing issue is whether activated astrocytes respond in a uniform manner or whether differences in astrocytes response upon brain injury exist. In recent studies, we performed experiments using primary cultured astrocytes from different brain regions for a better understanding of the function of astrocytes during brain pathology. Our results clearly demonstrate that astroglia actively respond to diverse pathological compounds by a selective expression pattern of growth factors. Astroglia cultures were exposed to different neurotoxic compounds at non-toxic concentrations, and growth factor expression was analyzed by PCR, oligomicroarray, and ELISA. Expression of IGF-1 was selectively down-regulated by exposure to LPS and TNF- $\alpha$, expression of bone morphogenetic protein 6 was decreased by all stimuli. In contrast, LPS, TNF- $\alpha$ and glutamate increased leukaemia inhibitory factor expression. Fibroblast growth factor-2 expression was up-regulated by LPS and TNF- $\alpha$, but down-regulated by hydrogen peroxide. Besides hydrogen peroxide, all other stimuli promoted VEGF-A expression. These findings make astrocytes likely candidates to participate in disease-specific characteristics of neuronal and oligodendroglial support or damage (Braun et al. 2009).

In another study, we investigated the potency of LPS to differentially stimulate astrocytes from the cortex and midbrain. Astrocytes from both brain areas already differed in their capacity and profile of cytokine expression under basal un-stimulated conditions. For example, GM-CSF, IL-13, and RANTES mRNA transcripts were present at significantly higher levels in the cortex compared to the midbrain, whereas IL-2, 
M-CSF, P-Selectin, and MIP-3 $\alpha$ were conversely reduced in cultured cortical astroglia. The exposure to LPS not only resulted in a similar induction of some proteins in both brain regions but also disclosed differential regulation of others. The expression of G-CSF, IL-2, and P-selectin was only stimulated in cortical cells by LPS. In contrast, IL-1 $\alpha$, IL-5, IL-6, MCP-1, MCSF, MIP-3 $\alpha$, RANTES, and TNF- $\alpha$ were all significantly increased after LPS challenge in midbrain and cortical astrocytes although to a different extent.

These data demonstrate that astrocytes reveal a region-specific basal profile of cytokine expression and a selective area-specific regulation of cytokines upon LPSinduced inflammation (Kipp et al. 2008). Our results highlight that the impact of astrocytes on MS pathology might differ between different brain regions. Since it is well-known that the composition of the inflammatory infiltrate changes during disease course (inflammation is less prominent in chronic disease stages), the function of astrocytes likely varies as disease progresses.

\section{Cuprizone-induced de- and remyelination as a model to study failure of remyelination}

It is apparent that astrocytes possess a dual role in MS disease progression. We assume that the activation of astrocytes is beneficial during the initial disease stages, however, after sustained tissue injury, a switch from a beneficial towards a deleterious astroglia function occurs. In a recent study, we aimed to identify the regenerationinducing population of astrocytes. This identification was performed using the toxic de-/remyelination cuprizone model. Cuprizone ingestion in mice induces a highly reproducible demyelination of distinct brain regions, such as the corpus callosum (CC) (Clarner et al. 2011, Groebe et al. 2009, Kipp et al. 2009, Norkute et al. 2009, Pott et al. 2009). After 5-6 weeks of cuprizone treatment, the CC is almost completely demyelinated, a process called "acute demyelination". This process is followed by spontaneous remyelination when mice are fed normal chow. In contrast, remyelination is highly impaired when cuprizone administration is prolonged (13 weeks or longer), a process called "chronic demyelination". By using this model, repair processes can be clearly defined i.e. reappearance of myelin in previously demyelinated areas. In other disease models, regeneration is more difficult to pin-point. It has been postulated that remyelination completely fails after a chronically cuprizone-induced demyelination (13 weeks) event (Vana et al. 2007, Harsan et al. 2008), whereas other reports suggest that remyelination does not completely fail but is delayed (Lindner et al. 2009). We reassessed the remyelination capacity after acute and chronic cuprizoneinduced demyelination. In these studies male mice were fed cuprizone $(0.2 \%)$ for 5 weeks to induce acute demyelination, or 13 weeks to induce chronic demyelination. Remyelination was analyzed after a 4-week period. Under these conditions, the $\mathrm{CC}$ is severely demyelinated after 5 and 13 weeks of cuprizone treatment as demonstrated by anti-PLP immunohistochemsitry (Figs 1b/c). The myelin status of the CC significantly improves after acute demyelination during a 4-week follow-up period shown by a recovery of PLP immunoreactivity (Figs 1d/e). In contrast, endogenous remyelination almost completely fails after chronic cuprizone exposure. Nevertheless, APC-positive oligodendrocytes are still present within the acutely and chronically demyelinated lesion (inserts in Figs 1d/e). Our findings indicate that in the chronically demyelinated $\mathrm{CC}$, remyelination is highly impaired despite repopulation with pre-mature oligodendrocytes, similar to what is found in chronic lesions of MS patients (Chang et al. 2002). To identify genes related to endogenous remyelination which are induced in the CC, Affymetrix GeneChip ${ }^{\circledR}$ arrays were applied. Brain lipid binding protein (BLBP) also termed fatty acid binding protein 7 (FABP7) was identified as being highly expressed in the remyelinating $\mathrm{CC}$. This class of fatty acid-binding proteins are cytoplasmic $14-15 \mathrm{kDa}$ proteins involved in fatty acid uptake, transport and metabolism. Nine FABP types can be discerned with a tissue specific distribution pattern (Veerkamp and Zimmerman 2001). Brain FABP, also called FABP7 or BLBP, is widely used as a radial glia cell marker (Bibel et al. 2004, Barry and McDermott 2005, Patrikios et al. 2006, Sibbe et al. 2009). Radial glia plays an essential role in the laminar organization of neurons in the cerebral cortex (Rakic 1971, 1972). Due to its abundant expression in the acutely demyelinated $\mathrm{CC}$, we assume that expression of FABP7 in activated astrocytes might play a role during remyelination.

\section{Expression of FABP7 in the normal and injured brains}

Schmid et al. (2006) used transgenic mice under the control of the FABP7 promoter to study the cellular distribution and morphology of FABP7-expressing cells. Their results suggest that during early postnatal days, 


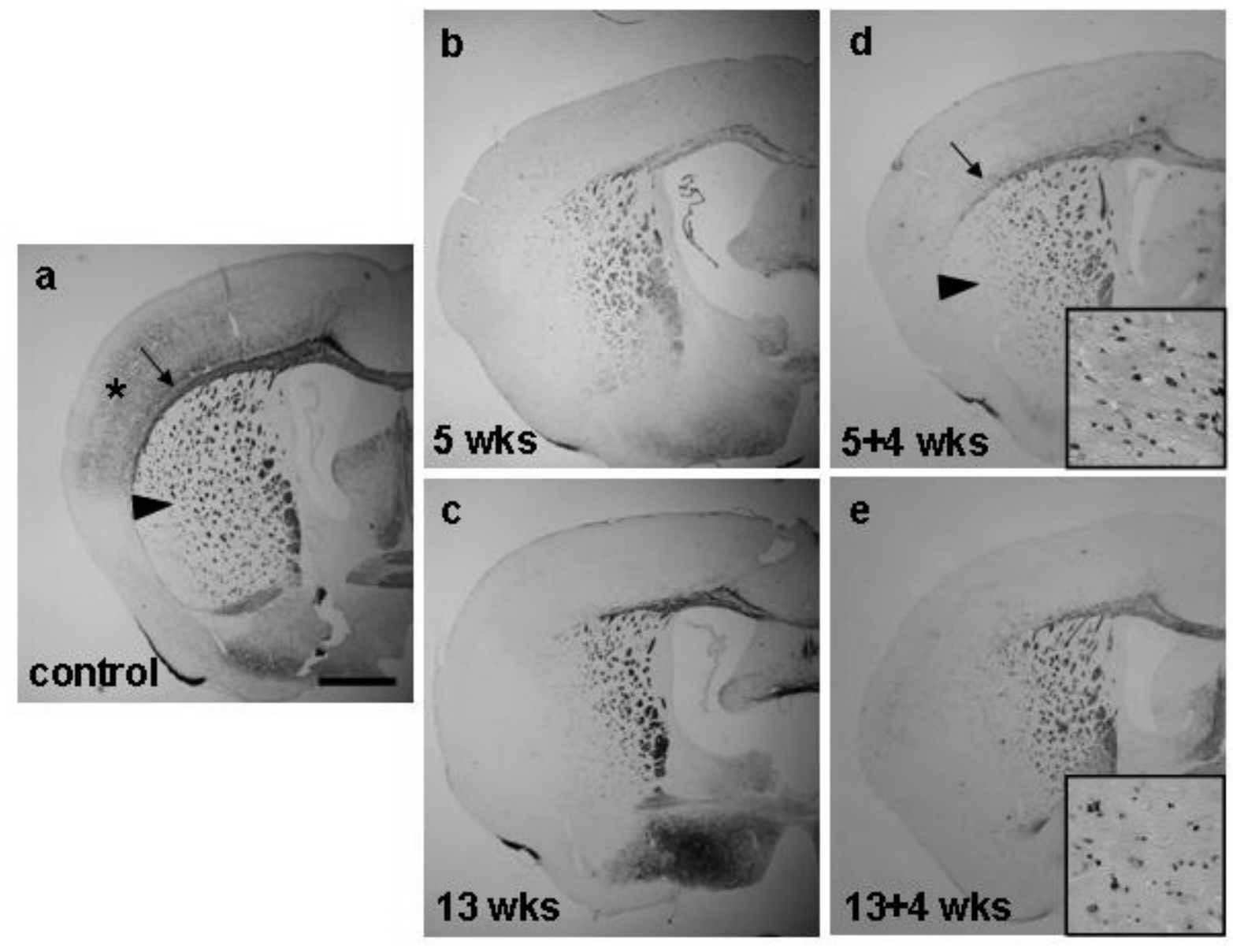

Fig. 1. Remyelination capacity after cuprizone-induced acute ( 5 weeks) and chronic (13 weeks) demyelination is shown by anti-PLP and anti-APC (inserts) staining, respectively. In control animals, the corpus callosum (CC) (arrow), cortex (star) and basal ganglia complex (arrowhead) are well-myelinated (a). (b) and (c) show that the CC and other brain regions are severely demyelinated after 5 (b) and 13 (c) weeks cuprizone treatment. Note that significant remyelination occurs after acute demyelination, indicated by the recovery of PLP immunoreactivity mainly within the lateral part of the CC (arrow in d) and the laterally orientated basal ganglia complex (arrowhead in d), whereas these regions are devoid of any $\mathrm{PLP}^{+}$fibers in the chronically demyelinated group (e). Both lesions contain APC $^{+}$ oligodendrocytes (inserts in d/e). Scale bars: $1 \mathrm{~mm}$ (a-e)

radial glia transform into $\mathrm{GFAP}^{+}$astrocytes and the FABP7 promoter remains active in astrocytes. Consistent with this, they observed FABP7 expression in GFAP ${ }^{+}$ astrocytes of the adult cerebral cortex and hippocampus. FABP7/GFAP double-positive cells were primarily found in the outer layers of the cortex extending to the pial surface and in cells distributed adjacent to the ventricles (Schmid et al. 2006). These results are in good agreement with our own observations. As shown in Figure 2, FABP7-expressing cells with a process towards the surface of the brain can be found in the subpial compartment in C57BL6 mice (Fig. 2A) and also in the normal appearing gray matter of MS patients (Fig. 2B). In addition, ovoid-shaped FABP7-expressing cells are seen within the murine white matter (Fig. 2D) and normal appearing white matter of humans MS subjects (Fig. 2E).

Results of several studies implicate that FABP7 is involved in pathological processes of the adult CNS. FABP7 expression is increased within different hippocampal sub-regions in response to cerebral ischemia in young adult monkeys (Ma et al. 2010). Transient, complete, whole-brain ischemia was induced in young adult monkeys (Macaca fuscata) by clamping the innominate and left subclavian arteries for $20 \mathrm{~min}$. These authors were able to show that FABP7 is preliminary expressed by astrocytes and progenitors of the noninjured hippocampal dentate gyrus and cornu ammonis region. Follwoing ischemia, FABP7 expression was increased within the hippocampus and co-localized to proliferating cells. White and colleagues (2010) investigated the expression of FABP7 in response to contusive spinal cord injury in mice (White et al.). In the control spinal cord, FABP7 expression was restricted to a small number of cell bodies in the gray matter, a few cell 

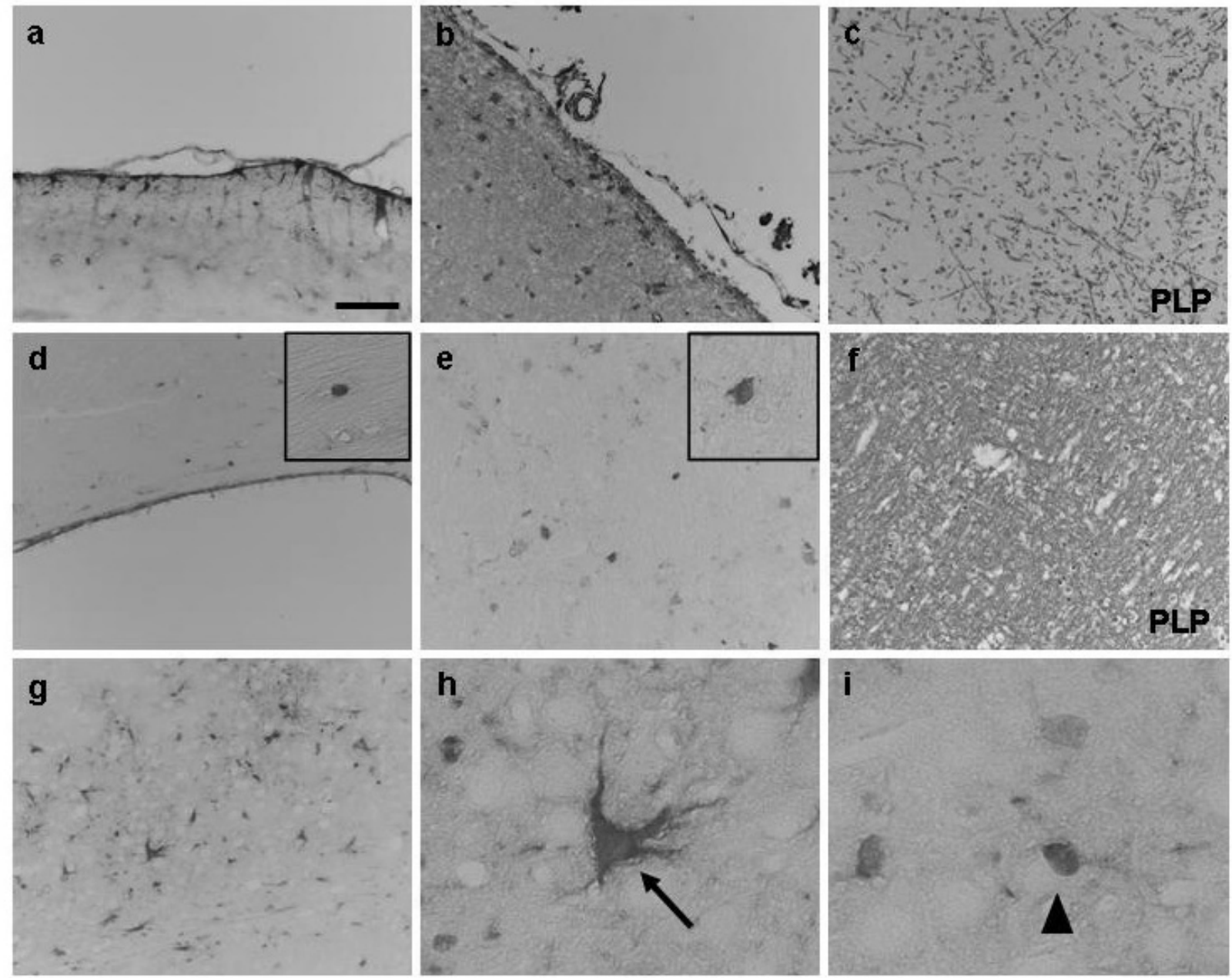

Fig. 2. Morphology of FABP7-expressing cells in the murine and human brain. (a) shows FABP7-expressing cells in the subpial compartment of control animals. (b) shows FABP7-expressing cells in the same compartment of the human brain surrounded by normal appearing gray matter (c). (d) shows round-shaped FABP7-expressing cells in the CC of control animals. (e) shows FABP7-expressing cells in the normal appearing human white matter with the respective anti-PLP staining (f). Inserts (d/e) show the same cells at higher magnification. ( $\mathbf{g}$ ) shows stellate-shaped (higher magnification in $\mathbf{h}$ ) and round-shaped (higher magnification in i) FABP7-expressing cells after cuprizone-induced demyelination (5 weeks, $0.2 \%$ ). Scale bars: $160 \mu \mathrm{m}$

bodies in the superficial dorsal horn, and cells contacting the pia mater in the periphery of the white matter. This study was the first to characterize the distribution of FABP7 immunoreactivity over time in the injured rodent spinal cord. In the lesion border and spared white matter (i.e. lesion border), FABP7 expression was strongly upregulated and co-localized with GFAP expression. Furthermore, transient induction of FABP7 expression occurred in cells lining the central canal and in a unique population of small cells found within the lesion and in gray matter rostral and caudal to the lesion border. A subset of these cells was labelled with BrdU. Seven days after the injury, this cell type was no longer seen. Additional experiments revealed that some of these cells were positive for nestin $24 \mathrm{~h}$ after the injury. The authors proposed that these cells represent precursors committed to differentiate into mature astrocytes.

After acute cuprizone-induced demyelination, we observed two distinct populations of FABP7expressing cells. As shown in Figures 2g-i, one population resembled multi-process-bearing astrocytes (arrow), whereas another population were round shaped without cell processes (arrowhead). Immunofluorescence double-labelling revealed that FABP7-expressing cells with an astrocytes-like morphology are GFAP-positive. In contrast, round shaped $\mathrm{FABP}^{+}$cells do not co-stain with GFAP. Thus, the presence of $\mathrm{FABP}^{+} / \mathrm{GAFP}^{+}$and $\mathrm{FABP}^{+} / \mathrm{GAFP}^{-}$cell populations are not restricted to contusive spinal cord injury but can also be found in the toxic demyelination model.

FABP7 expression is induced in astrocytes and Müller glial cells in rats subjected to kainate acid 
treatment which leads to neuronal degeneration in the retina (Chang et al. 2007). Thus, astrocytes appear to dedifferentiate after kainate acid-induced retinal degeneration. Bannerman and colleagues recently demonstrated that FABP7/GFAP double-positive cells accumulate within the spinal cord in MOG-induced EAE in mice (Bannerman et al. 2007). Twenty one days after immunization with MOG, FABP7-expressing cells with a multiprocess-bearing morphology appeared within and at the margin of the inflamed lesions. These studies clearly show that (i) FABP7 expression is dynamically regulated during various types of brain injury and (ii) is induced in activated $\mathrm{GFAP}^{+}$astrocytes as well as in not further characterized GFAP ${ }^{-}$cells.

\section{Role of FABP7 expression in astrocytes}

The putative function of FABP7 in the brain comes from studies of anaplastic astrocytomas (grade III astrocytoma) and glioblastoma multiforme (GBM; grade IV astrocytoma), collectively called malignant gliomas (MG) which are the most common cancer types in the CNS (Mita et al. 2007). FABP7 is found in astrocytoma tumor biopsies and in a subset of $\mathrm{MG}$ cell lines. Expression levels of FABP7 are increased in brain tumor tissue compared to the normal adult brain (Godbout et al. 1998, Sanai et al. 2005). Most importantly, FABP7 levels are associated with decreased survival times and/or tumor progression in patients with grade IV astrocytoma (Feng et al. 1994, Sanai et al. 2005). Notably, nuclear FABP7 staining had a clear negative correlation with survival of GBM patients (Liang et al. 2005). FABP7 appears to regulate cell morphology in MG cell lines (Mita et al. 2007). In vitro FABP7-negative U87 MG cells had a stellate appearance with short processes. Stable transfection of those cells with a human FABP7 expression construct induced the formation of extended bipolar processes often spanning considerable distances (up to $250 \mu \mathrm{m}$ ). These elongated processes were similar in appearance to radial glial processes that can span the entire width of the cortical wall during brain development. Concordantly, depletion of FABP7 in FABP7-expressing MG cell lines resulted in a loss of elongated processes which was associated with a reduced cell migration and invasion. On the subcellular level, FABP7 co-localizes with F-actin in U251 cells (Mita et al. 2007).

How might these findings be interpreted in the context of astrocyte-regulated remyelination? It is obvious that pro-myelinating factors such as IGF-1, FGF-2, and PDGF-A can interact with their target cells most efficiently if they are released in close vicinity to OPC. As an example, IGF binding protein regulates IGF1 protein tissue distribution and inhibits the binding of IGF-1 to its cognate receptor (Kooijman et al. 2009). Thus, increased astrocyte migration might stimulate remyelination by increasing local levels of IGF-1 in the peri-cellular space of OPC.

Function of FABP7-expressing astrocytes also depends on the presence or absence of FABP7 ligands such as fatty acids. In vitro ligand binding studies have shown that the polyunsaturated fatty acid (PUFA), $\omega-3$ docosahexaenoic acid (DHA; 22:6) is the preferred ligand of FABP7. FABP7 also binds $\omega-6$ arachidonic acid (AA; 20:4), albeit with a $\sim$-fold lower affinity (Balendiran et al. 2000). Highly unsaturated long-chain fatty acids alter the structure and function of membranes, increasing their fluidity, elasticity, and permeability, and potentially affecting signal transduction and gene expression (Hashimoto et al. 1999, Rojas et al. 2003, Stillwell and Wassall 2003). Preferential localization of FABP7 at the leading edges of astrocytes may result in increased PUFA content at these sites. Increased fluidity may directly influence cell motility or may activate cell signalling events associated with cell motility und thus further diminish the gap between OPC and astrocytes processes. Mita et al. (2010) showed that FABP7-induced MG cell migration is fatty acid ligand-dependent since growth of FABP7-expressing U87 cells in DHA resulted in a 5-fold decrease in cell migration studies. In contrast, $\mathrm{FABP}^{+}$ U87 cells cultured in AA showed a small but significant increase in cell migration. These results indicate a strong link between FABP7-mediated cell migration and presence of DHA or AA. To address whether the ratio of DHA:AA, as opposed to individual concentrations of DHA or AA, is driving the effects on cell migration, $\mathrm{U} 7-\mathrm{FABP}^{+}$MG cells were treated with varying concentrations of DHA and $\mathrm{AA}$, and their migration performance was measured. The ratio of DHA:AA determined the migration of FABP7-expressing U87 MG cells. When levels of AA exceeded those of DHA by 3fold or more, the inhibitory effects of DHA on cell migration were negated. These results are expected in light of in vitro data indicating that DHA has a 4-times greater binding affinity for FABP7 than AA (Balendiran et al. 2000). Moreover, these studies provide evidence that FABP7 localization to the nucleus is not required for FABP7-mediated cell migration; however, inhibition of 
migration by DHA is dependent on localization of FABP7 to the nucleus.

The cause of MS is unknown. The geographic distribution and epidemiological risk factors such as emigration suggest the importance of environmental factors (Ascherio and Munger 2007). Differences in the diet composition have been suggested as one explanation for the geographic distribution of MS. In a recent work, Bo et al. (2009) investigated the effects of dietary intervention on MRI activity and de- and remyelination in the cuprizone model (Torkildsen et al. 2009a, Torkildsen et al. 2009b). An interesting outcome of their studies was that mice fed on a diet with soybean-oil cuprizone (high $\omega-6 / \omega-3$ ratio) tended to a more extensive remyelination than mice fed cod liver-oil cuprizone (low $\omega-6 / \omega-3$ ratio). It would be interesting to determine whether the levels of individual PUFAs such as DHA and AA (or their respective ratio) differ in remyelinating veruses nonremyelinating MS lesions and, thus, might contribute to remyelination failure during chronic MS courses.

\section{Conclusion}

Demyelination is still regarded as a pathological hallmark of MS but it has become increasingly apparent in recent years that substantial axonal and neuronal loss are equally important features (Baracskay et al. 2002, Geurts and Barkhof 2008, Geurts et al. 2009). Remyelination is the best-documented and most robust example of tissue repair in the human CNS and is unequivocally neuroprotective in MS. Approximately $40 \%$ of post-mortem MS tissues demonstrate remyelination which can occur early and late during the course of MS (Patrikios et al. 2006, Franklin and Ffrench-Constant 2008, Irvine and Blakemore 2008). Remyelination is believed to restore the structural integrity of the axon-myelin unit and axonal conduction properties that are lost following demyelination (Smith et al. 1979, Halliday 1981). It is unresolved why in some patients remyelination is widespread while it is sparse in other patients. The importance of axonal damage and loss as the pathological basis for progressive loss of function in MS demands a better understanding of remyelination processes and possible reasons for its failure. Several mechanisms have been suggested that may result in a blockade of remyelination. The loss and destruction of OPC within the lesions in the course of repeated de- and remyelination (Prineas et al. 1993a, Prineas et al. 1993b) might play a role. In some lesions, however, progenitor cells are abundantly present (Scolding et al. 1998, Wolswijk 1998, Chang et al. 2000, Chang et al. 2002) but remyelination still fails either because axons are not permissive for remyelination (Charles et al. 2002) or the maturation of progenitor cells is inhibited (John et al. 2002). Taken together, results from our group and others strongly implicate that astrocytes actively participate in the course of MS disease. Impaired FABP7 signalling might be a major characteristic for the failure of remyelination and progression of clinical disability. Further studies have to verify our hypothesis.

\section{Conflict of Interest}

There is no conflict of interest.

\section{References}

ARNETT HA, MASON J, MARINO M, SUZUKI K, MATSUSHIMA GK, TING JP: TNF alpha promotes proliferation of oligodendrocyte progenitors and remyelination. Nat Neurosci 4: 1116-1122, 2001.

ARNETT HA, WANG Y, MATSUSHIMA GK, SUZUKI K, TING JP: Functional genomic analysis of remyelination reveals importance of inflammation in oligodendrocyte regeneration. $J$ Neurosci 23: 9824-9832, 2003.

ASCHERIO A, MUNGER KL: Environmental risk factors for multiple sclerosis. Part II: Noninfectious factors. Ann Neurol 61: 504-513, 2007.

BACK SA, TUOHY TM, CHEN H, WALLINGFORD N, CRAIG A, STRUVE J, LUO NL, BANINE F, LIU Y, CHANG A, TRAPP BD, BEBO BF Jr, RAO MS, SHERMAN LS: Hyaluronan accumulates in demyelinated lesions and inhibits oligodendrocyte progenitor maturation. Nat Med 11: 966-972, 2005.

BALENDIRAN GK, SCHNUTGEN F, SCAPIN G, BORCHERS T, XHONG N, LIM K, GODBOUT R, SPENER F, SACCHETTINI JC: Crystal structure and thermodynamic analysis of human brain fatty acid-binding protein. J Biol Chem 275: 27045-27054, 2000.

BANNERMAN P, HAHN A, SOULIKA A, GALLO V, PLEASURE D: Astrogliosis in EAE spinal cord: derivation from radial glia, and relationships to oligodendroglia. Glia 55: 57-64, 2007. 
BARACSKAY KL, DUCHALA CS, MILLER RH, MACKLIN WB, TRAPP BD: Oligodendrogenesis is differentially regulated in gray and white matter of jimpy mice. J Neurosci Res 70: 645-654, 2002.

BARRY D, MCDERMOTT K: Differentiation of radial glia from radial precursor cells and transformation into astrocytes in the developing rat spinal cord. Glia 50: 187-197, 2005.

BIANCOTTI JC, KUMAR S, DE VELLIS J: Activation of inflammatory response by a combination of growth factors in cuprizone-induced demyelinated brain leads to myelin repair. Neurochem Res 33: 2615-2628, 2008.

BIBEL M, RICHTER J, SCHRENK K, TUCKER KL, STAIGER V, KORTE M, GOETZ M, BARDE YA: Differentiation of mouse embryonic stem cells into a defined neuronal lineage. Nat Neurosci 7: 1003-1009, 2004.

BRAUN A, DANG J, JOHANN S, BEYER C, KIPP M: Selective regulation of growth factor expression in cultured cortical astrocytes by neuro-pathological toxins. Neurochem Int 55: 610-618, 2009.

BRENNER M, JOHNSON AB, BOESPFLUG-TANGUY O, RODRIGUEZ D, GOLDMAN JE, MESSING A: Mutations in GFAP, encoding glial fibrillary acidic protein, are associated with Alexander disease. Nat Genet 27: 117-120, 2001.

CHANG A, NISHIYAMA A, PETERSON J, PRINEAS J, TRAPP BD: NG2-positive oligodendrocyte progenitor cells in adult human brain and multiple sclerosis lesions. J Neurosci 20: 6404-6412, 2000.

CHANG A, TOURTELLOTTE WW, RUDICK R, TRAPP BD: Premyelinating oligodendrocytes in chronic lesions of multiple sclerosis. N Engl J Med 346: 165-173, 2002.

CHANG ML, WU CH, JIANG-SHIEH YF, SHIEH JY, WEN CY: Reactive changes of retinal astrocytes and Muller glial cells in kainate-induced neuroexcitotoxicity. J Anat 210: 54-65, 2007.

CHARLES P, REYNOLDS R, SEILHEAN D, ROUGON G, AIGROT MS, NIEZGODA A, ZALC B, LUBETZKI C: Re-expression of PSA-NCAM by demyelinated axons: an inhibitor of remyelination in multiple sclerosis? Brain 125: 1972-1979, 2002.

CLARNER T, BUSCHMANN JP, BEYER C, KIPP M: Glial amyloid precursor protein expression is restricted to astrocytes in an experimental toxic model of multiple sclerosis. $J$ Mol Neurosci 43: 268-274, 2011.

FAULKNER JR, HERRMANN JE, WOO MJ, TANSEY KE, DOAN NB, SOFRONIEW MV: Reactive astrocytes protect tissue and preserve function after spinal cord injury. J Neurosci 24: 2143-2155, 2004.

FENG L, HATTEN ME, HEINTZ N: Brain lipid-binding protein BLBP: a novel signaling system in the developing mammalian CNS. Neuron 12: 895-908, 1994.

FRANKLIN RJ, FFRENCH-CONSTANT C: Remyelination in the CNS: from biology to therapy. Nat Rev Neurosci 9: 839-855, 2008.

FURER M, HARTLOPER V, WILKINS J, NATH A: Lymphocyte emperipolesis in human glial cells. Cell Adhes Commun 1: 223-237, 1993.

GEURTS JJ, BARKHOF F: Grey matter pathology in multiple sclerosis. Lancet Neurol 7: 841-851, 2008.

GEURTS JJ, STYS PK, MINAGAR A, AMOR S, ZIVADINOV R: Gray matter pathology in chronic MS: modern views on an early observation. $J$ Neurol Sci 282: 12-20, 2009.

GHATAK NR: Occurrence of oligodendrocytes within astrocytes in demyelinating lesions. $J$ Neuropathol Exp Neurol 51: 40-46, 1992.

GODBOUT R, BISGROVE DA, SHKOLNY D, DAY RS 3rd: Correlation of B-FABP and GFAP expression in malignant glioma. Oncogene 16: 1955-1962, 1998.

GOLD R, LININGTON C, LASSMANN H: Understanding pathogenesis and therapy of multiple sclerosis via animal models: 70 years of merits and culprits in experimental autoimmune encephalomyelitis research. Brain 129: 1953-1971, 2006.

GROEBE A, CLARNER T, BAUMGARTNER W, DANG J, BEYER C, KIPP M: Cuprizone treatment induces distinct demyelination, astrocytosis, and microglia cell invasion or proliferation in the mouse cerebellum. Cerebellum 8: 163-174, 2009.

HALLIDAY AM: Visual evoked potentials in demyelinating disease. Adv Neurol 31: 201-215, 1981. 
HARSAN LA, STEIBEL J, ZAREMBA A, AGIN A, SAPIN R, POULET P, GUIGNARD B, PARIZEL N, GRUCKER D, BOEHM N, MILLER RH, GHANDOUR MS: Recovery from chronic demyelination by thyroid hormone therapy: myelinogenesis induction and assessment by diffusion tensor magnetic resonance imaging. J Neurosci 28: 14189-14201, 2008.

HASHIMOTO M, HOSSAIN S, YAMASAKI H, YAZAWA K, MASUMURA S: Effects of eicosapentaenoic acid and docosahexaenoic acid on plasma membrane fluidity of aortic endothelial cells. Lipids 34: 1297-1304, 1999.

IRVINE KA, BLAKEMORE WF: Remyelination protects axons from demyelination-associated axon degeneration. Brain 131: 1464-1477, 2008.

JARIUS S, PAUL F, FRANCIOTTA D, WATERS P, ZIPP F, HOHLFELD R, VINCENT A, WILDEMANN B: Mechanisms of disease: aquaporin-4 antibodies in neuromyelitis optica. Nat Clin Pract Neurol 4: 202-214, 2008.

JARIUS S, WILDEMANN B: AQP4 antibodies in neuromyelitis optica: diagnostic and pathogenetic relevance. Nat Rev Neurol 6: 383-392, 2010.

JOHANN S, KAMPMANN E, DENECKE B, ARNOLD S, KIPP M, MEY J, BEYER C: Expression of enzymes involved in the prostanoid metabolism by cortical astrocytes after LPS-induced inflammation. $J$ Mol Neurosci 34: 177-185, 2008.

JOHN GR, SHANKAR SL, SHAFIT-ZAGARDO B, MASSIMI A, LEE SC, RAINE CS, BROSNAN CF: Multiple sclerosis: re-expression of a developmental pathway that restricts oligodendrocyte maturation. Nat Med $\mathbf{8}$ : 1115-1121, 2002.

KARAKAYA S, KIPP M, BEYER C: Oestrogen regulates the expression and function of dopamine transporters in astrocytes of the nigrostriatal system. J Neuroendocrinol 19: 682-690, 2007.

KIPP M, CLARNER T, DANG J, COPRAY S, BEYER C: The cuprizone animal model: new insights into an old story. Acta Neuropathol 118: 723-736, 2009.

KIPP M, NORKUTE A, JOHANN S, LORENZ L, BRAUN A, HIEBLE A, GINGELE S, POTT F, RICHTER J, BEYER C: Brain-region-specific astroglial responses in vitro after LPS exposure. J Mol Neurosci 35: 235-243, 2008.

KOOIJMAN R, SARRE S, MICHOTTE Y, DE KEYSER J: Insulin-like growth factor I: a potential neuroprotective compound for the treatment of acute ischemic stroke? Stroke 40: e83-e88, 2009.

LASSMANN H: Multiple sclerosis pathology: evolution of pathogenetic concepts. Brain Pathol 15: 217-222, 2005.

LASSMANN H: Models of multiple sclerosis: new insights into pathophysiology and repair. Curr Opin Neurol 21: 242-247, 2008.

LENNON VA, WINGERCHUK DM, KRYZER TJ, PITTOCK SJ, LUCCHINETTI CF, FUJIHARA K, NAKASHIMA I, WEINSHENKER BG: A serum autoantibody marker of neuromyelitis optica: distinction from multiple sclerosis. Lancet 364: 2106-2112, 2004.

LI R, MESSING A, GOLDMAN JE, BRENNER M: GFAP mutations in Alexander disease. Int J Dev Neurosci 20: 259-268, 2002.

LIANG Y, DIEHN M, WATSON N, BOLLEN AW, ALDAPE KD, NICHOLAS MK, LAMBORN KR, BERGER MS, BOTSTEIN D, BROWN PO, ISRAEL MA: Gene expression profiling reveals molecularly and clinically distinct subtypes of glioblastoma multiforme. Proc Natl Acad Sci U S A 102: 5814-5819, 2005.

LIN W, KEMPER A, DUPREE JL, HARDING HP, RON D, POPKO B: Interferon-gamma inhibits central nervous system remyelination through a process modulated by endoplasmic reticulum stress. Brain 129: 1306-1318, 2006.

LINDNER M, FOKUHL J, LINSMEIER F, TREBST C, STANGEL M: Chronic toxic demyelination in the central nervous system leads to axonal damage despite remyelination. Neurosci Lett 453: 120-125, 2009.

MA CS, NICHOLS KE, TANGYE SG: Regulation of cellular and humoral immune responses by the SLAM and SAP families of molecules. Annu Rev Immunol 25: 337-379, 2007.

MA D, ZHANG M, MORI Y, YAO C, LARSEN CP, YAMASHIMA T, ZHOU L: Cellular localization of epidermaltype and brain-type fatty acid-binding proteins in adult hippocampus and their response to cerebral ischemia. Hippocampus 20: 811-819, 2010. 
MANA P, LINARES D, FORDHAM S, STAYKOVA M, WILLENBORG D: Deleterious role of IFNgamma in a toxic model of central nervous system demyelination: Am J Pathol 168: 1464-1473, 2006.

MASON JL, SUZUKI K, CHAPLIN DD, MATSUSHIMA GK: Interleukin-1beta promotes repair of the CNS. J Neurosci 21: 7046-7052, 2001.

MESSING A, HEAD MW, GALLES K, GALBREATH EJ, GOLDMAN JE, BRENNER M: Fatal encephalopathy with astrocyte inclusions in GFAP transgenic mice. Am J Pathol 152: 391-398, 1998.

MITA R, COLES JE, GLUBRECHT DD, SUNG R, SUN X, GODBOUT R: B-FABP-expressing radial glial cells: the malignant glioma cell of origin? Neoplasia 9: 734-744, 2007.

MOORE CS, ABDULLAH SL, BROWN A, ARULPRAGASAM A, CROCKER SJ: How factors secreted from astrocytes impact myelin repair. $J$ Neurosci Res 89: 13-21, 2011.

NJENGA MK, MURRAY PD, MCGAVERN D, LIN X, DRESCHER KM, RODRIGUEZ M: Absence of spontaneous central nervous system remyelination in class II-deficient mice infected with Theiler's virus. J Neuropathol Exp Neurol 58: 78-91, 1999.

NORKUTE A, HIEBLE A, BRAUN A, JOHANN S, CLARNER T, BAUMGARTNER W, BEYER C, KIPP M: Cuprizone treatment induces demyelination and astrocytosis in the mouse hippocampus. J Neurosci Res $\mathbf{8 7}$ : 1343-1355, 2009.

PATANI R, BALARATNAM M, VORA A, REYNOLDS R: Remyelination can be extensive in multiple sclerosis despite a long disease course. Neuropathol Appl Neurobiol 33: 277-287, 2007.

PATRIKIOS P, STADELMANN C, KUTZELNIGG A, RAUSCHKA H, SCHMIDBAUER M, LAURSEN H, SORENSEN PS, BRUCK W, LUCCHINETTI C, LASSMANN H: Remyelination is extensive in a subset of multiple sclerosis patients. Brain 129: 3165-3172, 2006.

PEKNY M, LEVEEN P, PEKNA M, ELIASSON C, BERTHOLD CH, WESTERMARK B, BETSHOLTZ C: Mice lacking glial fibrillary acidic protein display astrocytes devoid of intermediate filaments but develop and reproduce normally. Embo J 14: 1590-1598, 1995.

PEKNY M, NILSSON M: Astrocyte activation and reactive gliosis. Glia 50: 427-434. 2005.

POTT F, GINGELE S, CLARNER T, DANG J, BAUMGARTNER W, BEYER C, KIPP M: Cuprizone effect on myelination, astrogliosis and microglia attraction in the mouse basal ganglia. Brain Res 1305: 137-149, 2009.

PRINEAS JW, BARNARD RO, KWON EE, SHARER LR, CHO ES: Multiple sclerosis: remyelination of nascent lesions. Ann Neurol 33: 137-151, $1993 \mathrm{a}$.

PRINEAS JW, BARNARD RO, REVESZ T, KWON EE, SHARER L, CHO E: Multiple sclerosis. Pathology of recurrent lesions. Brain 116 (Pt 3): 681-693, 1993 b.

QUINLAN RA, BRENNER M, GOLDMAN JE, MESSING A: GFAP and its role in Alexander disease. Exp Cell Res 313: 2077-2087, 2007.

RAKIC P: Neuron-glia relationship during granule cell migration in developing cerebellar cortex. A Golgi and electronmicroscopic study in Macacus Rhesus. J Comp Neurol 141: 283-312, 1971.

RAKIC P: Mode of cell migration to the superficial layers of fetal monkey neocortex. J Comp Neurol 145: 61-83, 1972.

RASH JE, YASUMURA T, DUDEK FE, NAGY JI: Cell-specific expression of connexins and evidence of restricted gap junctional coupling between glial cells and between neurons. J Neurosci 21: 1983-2000, 2001.

ROJAS CV, MARTINEZ JI, FLORES I, HOFFMAN DR, UAUY R: Gene expression analysis in human fetal retinal explants treated with docosahexaenoic acid. Invest Ophthalmol Vis Sci 44: 3170-3177, 2003.

SAIKALI P, CAYROL R, VINCENT T: Anti-aquaporin-4 auto-antibodies orchestrate the pathogenesis in neuromyelitis optica. Autoimmun Rev 9: 132-135, 2009.

SANAI N, ALVAREZ-BUYLLA A, BERGER MS: Neural stem cells and the origin of gliomas. $N$ Engl J Med 353: 811-822, 2005.

SAWAISHI Y: Review of Alexander disease: beyond the classical concept of leukodystrophy. Brain Dev 31: 493-498, 2009.

SCHMID RS, YOKOTA Y, ANTON ES: Generation and characterization of brain lipid-binding protein promoterbased transgenic mouse models for the study of radial glia. Glia 53: 345-351, 2006. 
SCOLDING N, FRANKLIN R, STEVENS S, HELDIN CH, COMPSTON A, NEWCOMBE J: Oligodendrocyte progenitors are present in the normal adult human CNS and in the lesions of multiple sclerosis. Brain $121(\mathrm{Pt}$ 12): 2221-2228, 1998.

SIBBE M, FORSTER E, BASAK O, TAYLOR V, FROTSCHER M: Reelin and Notch1 cooperate in the development of the dentate gyrus. $J$ Neurosci 29: 8578-8585, 2009.

SMITH KJ, BLAKEMORE WF, MCDONALD WI: Central remyelination restores secure conduction. Nature 280: 395396, 1979.

STILLWELL W, WASSALL SR: Docosahexaenoic acid: membrane properties of a unique fatty acid. Chem Phys Lipids 126: 1-27, 2003.

TORKILDSEN O, BRUNBORG LA, MILDE AM, MORK SJ, MYHR KM, BO L: A salmon based diet protects mice from behavioural changes in the cuprizone model for demyelination. Clin Nutr 28: 83-87, 2009a.

TORKILDSEN O, BRUNBORG LA, THORSEN F, MORK SJ, STANGEL M, MYHR KM, BO L: Effects of dietary intervention on MRI activity, de- and remyelination in the cuprizone model for demyelination. Exp Neurol 215: 160-166, 2009b.

VAN DER VALK P, DE GROOT CJ: Staging of multiple sclerosis (MS) lesions: pathology of the time frame of MS. Neuropathol Appl Neurobiol 26: 2-10, 2000.

VANA AC, FLINT NC, HARWOOD NE, LE TQ, FRUTTIGER M, ARMSTRONG RC: Platelet-derived growth factor promotes repair of chronically demyelinated white matter. J Neuropathol Exp Neurol 66: 975-988, 2007.

VEERKAMP JH, ZIMMERMAN AW: Fatty acid-binding proteins of nervous tissue. J Mol Neurosci 16: 133-142, discussion 151-157, 2001.

VENANCE L, CORDIER J, MONGE M, ZALC B, GLOWINSKI J, GIAUME C: Homotypic and heterotypic coupling mediated by gap junctions during glial cell differentiation in vitro. Eur J Neurosci 7: 451-461, 1995.

WHITE RE, MCTIGUE DM, JAKEMAN LB: Regional heterogeneity in astrocyte responses following contusive spinal cord injury in mice. J Comp Neurol 518: 1370-1390, 2010.

WOLSWIJK G: Chronic stage multiple sclerosis lesions contain a relatively quiescent population of oligodendrocyte precursor cells. J Neurosci 18: 601-609, 1998. 